\title{
AS BARREIRAS CONDICIONANTES NA EVOLUÇÃO DE SÃO CARLOS
}

\section{BOUNDARY CONDITIONS IN THE SÃO CARLOS' CITY EVOLUTION}

\section{Sérgio Antonio Röhm ${ }^{1}$; José Fabrício Ferreira ${ }^{2}$}

${ }^{1,2}$ Universidade Federal de São Carlos, UFSCar, Centro de Ciências Exatas e de Tecnologia, Departamento de Engenharia Civil/Planejamento Urbano e-mail:sarohm@yahoo.com.br; jfabferr@terra.com.br

\section{RESUMO}

Este texto aborda e discute os aspectos históricos gerais que vêm influenciando a formação das condições de acessibilidade intraurbana, na tentativa de interpretar a essência do valor do lote urbano da cidade de São Carlos - SP. Procurou-se reunir elementos espaciais para justificar porque São Carlos vem se desenvolvendo no local onde está e como o valor da terra esteve desde o início associado à acessibilidade ao centro convergente. $\mathrm{O}$ crescimento da aglomeração tem sido marcado por diversas tendências. Portanto, não basta interpretar as estatísticas censitárias, sendo necessário analisar e compreender como e porque se dão os padrões espaciais de distribuição de riqueza e pobreza pelo solo urbano. A geografia local tem influenciado diretamente os processos de estruturação intra-urbana, a começar pelos obstáculos ou os atrativos naturais do território. As feições naturais são importantes, porém não são decisivas para o valor do lote urbano. A cidade, como produto humano, tem sua própria lógica de valorização.

Palavras-chave: Condições de contorno. Engenharia urbana. Planejamento urbano. Lote. Uso e ocupação do solo urbano

\section{ABSTRACT}

This paper discusses the general historical aspects that has influenced the formation of the intra-urban accessibility conditions, angling for to interpret the essence of the urban lot value in the São Carlos' City, São Paulo'State. It was tried to group space elements to explain why São Carlos is developing itself in the place where it is and how the land value has been, since the beginning, associated with the accessibility to a convergent center. The agglomeration growth has been marked for 
several trends. So, it is not sufficient to interpret of the census data statistics. It is necessary to analyze and to understand how and why the pattern of distribution of wealth and poverty has been established throughout urban land. The local geography has influenced directly on the processes of intra-urban arrangement, considering even favorable and negative natural aspects of the territory. The natural aspects are important; however, they are not decisive for the urban lot value. The city, as human product, has its own logic of valuation.

Keywords: Boundary conditions. Urban. Urban planning, urban lot. Use and occupation of urban land.

\section{INTRODUÇÃO}

Este texto aborda e discute os aspectos históricos gerais que vêm influenciando a formação das condições de acessibilidade intra-urbana, na tentativa de contribuir para a interpretação da natureza do valor do lote urbano da cidade de São Carlos SP.

As aglomerações urbanas são constituídas por diversas localizações, que têm a acessibilidade como um dos principais atributos, com grande influência na valoração do lote urbano. As localizações intra-urbanas que apresentam a característica de minimizar o conjunto dos tempos de deslocamento diário de pessoas, tais como os trajetos casa-trabalho, casa-lazer, casa-escola, casa-consumo, dentre outros, são mais valorizadas.

Há duas forças que dispõem de ampla liberdade para escolha de suas localizações. Uma delas é de natureza extra-urbana, regional, ligada à esfera da produção, geralmente industrial. A outra é de natureza local, fortemente associada à esfera do consumo e constitui-se na localização dos bairros residenciais das camadas de maior renda. O território restante é disputado pelos diversos segmentos de menor poder econômico no âmbito do mercado imobiliário, que expressa em preços o valor do solo urbano.

Neste contexto, as barreiras são relevantes porque desvalorizam certas localizações em relação a outras. Estas barreiras são de ordem natural, como a conformação do relevo e a hidrografia e sob a influência destes, freqüentemente, são traçadas as ferrovias e as rodovias.

Há quatro grandes barreiras intra-urbanas em São Carlos: a delimitação da planície central, a ferrovia, a Rodovia Washington Luiz e a encosta sul. Cada barreira tem sua própria natureza e suas características próprias de transposição que impõem diferentes graus de dificuldades aos ocupantes.

Enquanto as barreiras minimizam a acessibilidade, as vias a maximizam. Assim, ambas atraem padrões específicos de parcelamento e ocupação do solo que são, justamente, as localizações onde se observam grandes possibilidades de 
ocorrência de desvios das características dos lotes no cenário de todo espaço intraurbano.

As ferrovias e as rodovias demonstram o paradoxo das vias constituírem barreiras, embora promovam acessibilidade. A imobilidade destas estruturas de acesso induz a consolidação dos usos e suas estruturas físicas, contribuindo para acentuar os contrastes e paradigmas da ocupação industrial e dos bairros residenciais de alto padrão.

Este processo de consolidação de barreiras, reafirmação de trajetos intra e extraurbanos e consolidação de infra-estruturas vem ocorrendo gradativamente, desde os primórdios da formação do núcleo urbano do município de São Carlos.

\section{A PLANÍCIE CENTRAL COMO LOCALIZAÇÃO FAVORÁVEL}

São Carlos do Pinhal teve seu marco inicial (Figura 1) implantado por Antônio Carlos de Arruda Botelho, conforme cita NEVES (1983): "Em 1855, acompanhado de quatro escravos, um dos quais o seu feitor Felício, derrubou, destocou, roçou e queimou dois alqueires de mata, traçando como eixo a Rua de São Carlos e enquadrando o pátio, onde se ergueria a capela." No local desta capela original encontra-se hoje a Catedral. Separada pela Avenida São Carlos, a espinha dorsal, encontra-se a praça frontal, o antigo Jardim Público, hoje Praça Coronel Paulino Carlos Botelho. Segundo Braga (1894), "Toda a área da actual cidade e seus suburbios era campo e matta."

A maior parte do território do município de São Carlos encontra-se a norte do núcleo urbano. A extensão até o Rio Mogi é vasta e ricamente irrigada. O início da ocupação territorial rural caracterizou-se pela proximidade aos corpos d'água, principalmente às nascentes, de forma que um pequeno núcleo ou sede de fazenda pudesse usufruir da água em um curso independente dos demais. Quanto mais ramificada a bacia hidrográfica, maior a ocupação por edificações e instalações, começando por suas nascentes, próximas aos caminhos induzidos pelos divisores de águas. Assim, a maioria das fazendas encontrava-se na parte setentrional, sendo natural que esta região fosse mais habitada e que daí viesse à maior parte da produção agrícola municipal. Opostamente, a sul do núcleo urbano, o território do município é consideravelmente menor e menos ocupado por fazendas, embora algumas fossem tão ou mais produtivas quanto outras do norte. A ocupação expressiva por fazendas ao norte tende a tornar a rede de vias mais densa, além de favorecer a subdivisão das fazendas em propriedades menores. 


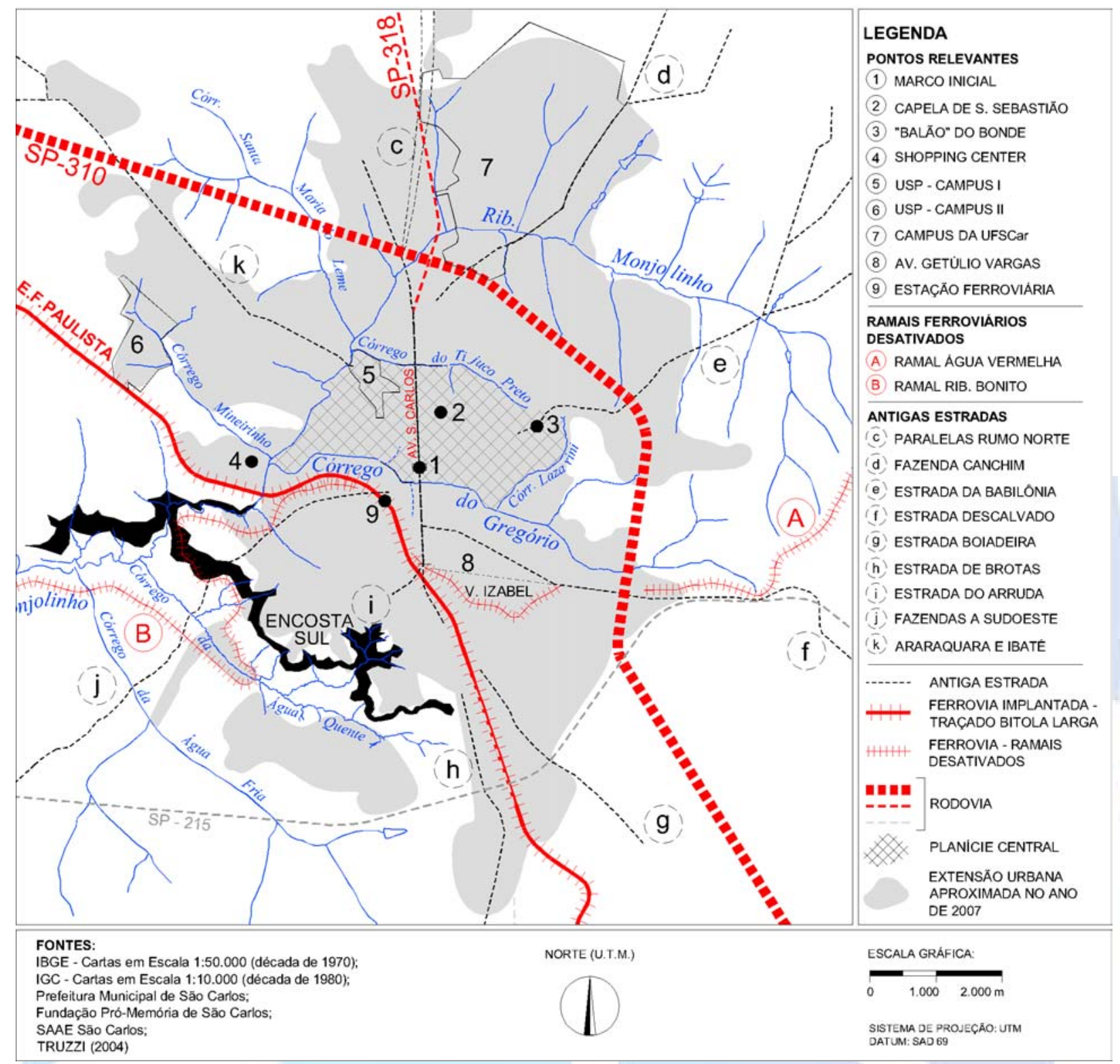

FIGURA 1. Mapa hidrográfico da bacia do Ribeirão Monjolinho e as principais vias de transporte do município de São Carlos.

Neste contexto (Figura 2) formaram-se Santa Eudóxia e Água Vermelha. Água Vermelha ocupa uma posição central da região mais adensada, no Bairro do Lobo. Santa Eudóxia, mais antiga e distante, polarizou a ocupação no extremo norte do município. Nesta época, havia três sesmarias no território de São Carlos, como relatam Braga (1894) e Neves (1983). São elas: a Sul, a Sesmaria do Pinhal, propriedade da família Botelho; divisando a norte, a Sesmaria do Monjolinho, pertencente a João Alves de Oliveira; e mais a norte, a Sesmaria do Quilombo, abrangendo o território dos atuais distritos de Santa Eudóxia e Água Vermelha.

O marco inicial de São Carlos, de fato, instalou-se em uma região de fronteiras de sesmarias. A longa citação seguinte revela a aversão de certos proprietários de sesmarias ante a proximidade de um núcleo urbano nascente. João Alves de Oliveira a levou às últimas conseqüências. Para ele, um local conveniente era justamente próximo 
à sede da Fazenda do Pinhal. Braga (1894), referindo-se ao topo da planície como um local naturalmente mais atrativo para a fundação da cidade, em torno de uma capela, discorre: "o local preferido era a bella esplanada das alturas do actual largo de S. Sebastião. Sobreveio, porém, um obstáculo que não poude ser vencido. João Alves de Oliveira, proprietário da Sesmaria do Monjollinho, era adverso à fundação do povoado. ... Todavia, não se oppunha, afinal, a que a capella fosse erigida ao sul donde está hoje a cidade, além da actual Villa Izabel, no ultimo planalto campestre que a linha-ferrea atravessa antes de chegar á estação de S. Carlos. Assim se affastaria mais do seu estabelecimento agrícola (Fazenda Velha, a que já alludimos), o núcleo de população premeditado." ... "Capricho por capricho, foi resolvida a creação da capella nas terras da sesmaria do Pinhal; mas no ponto que mais se approximava do local primitivamente lembrado."

A ocupação do topo da planície central só ocorreu após a morte de João Alves. Em 1867, sua viúva Dona Alexandrina doou uma área de 300 por 500 braças à Câmara Municipal de São Carlos, as mesmas dimensões do terreno doado por Jesuíno de Arruda para a constituição do Patrimônio da Capela, em 1858. Considerando uma braça equivalente a 1,83 metros, uma medida de 300 por 500 braças equivaleria a aproximadamente 50 hectares. Segundo o trecho da escritura de doação (NEVES, 1983), "comessando no rumo que passa no Pateo da Igreja Matriz, medindo-se as quinhentas braças ao longo da Rua do Commercio (hoje denominada de Avenida São Carlos), e cento e cincoenta braças de lado a lado da mesma rua."

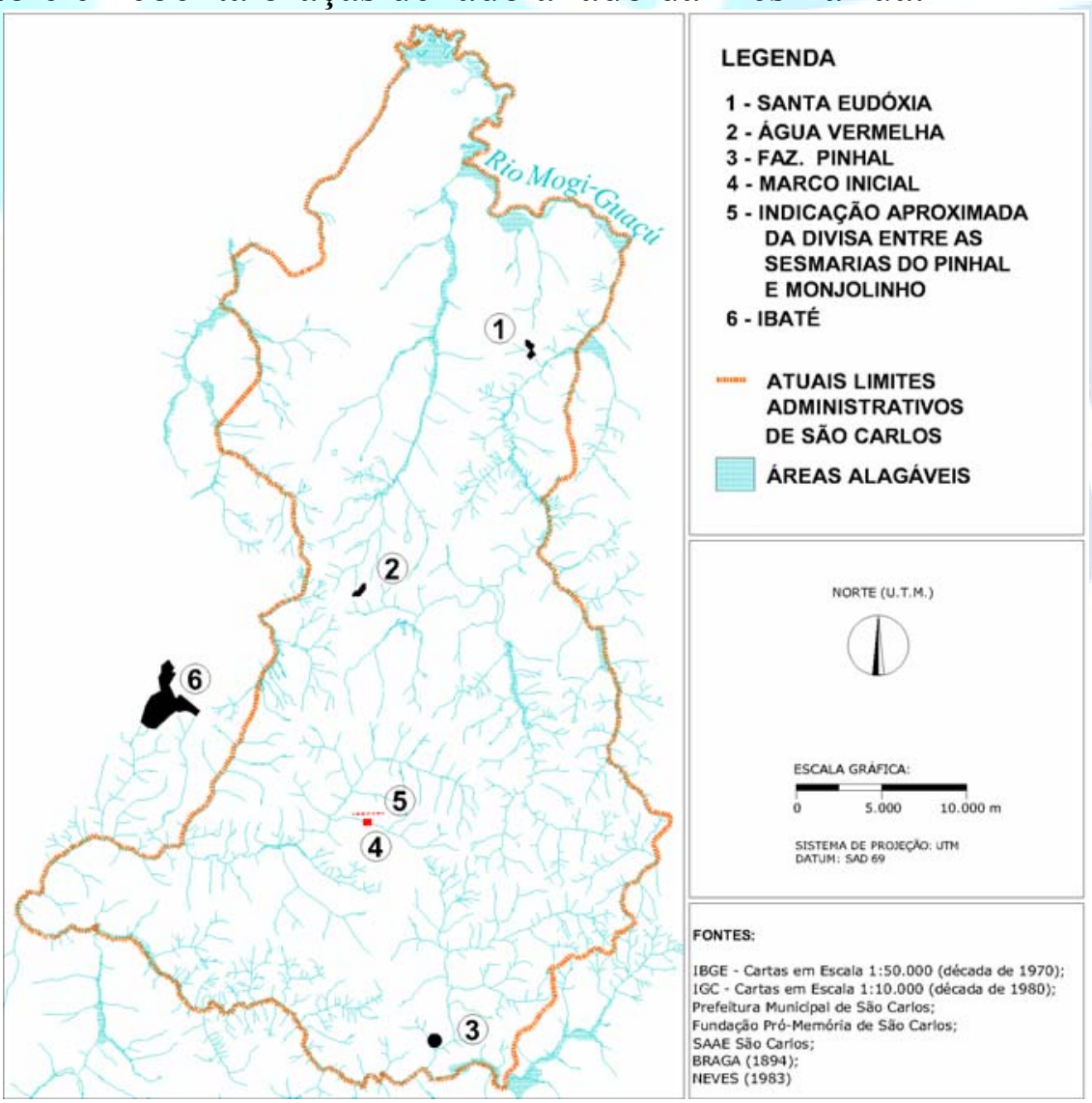

FIGURA 2. Características geográficas do município. 
A ferrovia, inaugurada 29 anos após a construção do marco inicial (15 de outubro de 1884), marca o final de um período relativamente curto, mas relevante na história são-carlense. Este período pré-ferroviário é caracterizado pela formação e expansão inicial da sede do núcleo urbano de São Carlos.

Esta configuração inicial, que remonta à iminência dos primeiros melhoramentos urbanos, é marcada planimetricamente pela malha viária ortogonal, orientada pelos pontos cardeais e pela forma quadrada dos quarteirões. Este padrão perfeitamente regular consolidou-se no início, mas raramente se repete no decorrer do processo de expansão urbana de São Carlos, principalmente na transposição da planície central para as planícies vizinhas. A malha urbana perfeitamente regular tende a identificar-se com a velha ordem imperial. A qualidade da ocupação da planície central delineia o privilégio desta localização sobre as demais.

Os cursos d'água que formam os limites desta planície central são (Figura 1): Córrego Gregório, Córrego Tijuco Preto, Ribeirão Monjolinho e Córrego Lazarini. Estes corpos d'água constituíram barreiras naturais de transposição. Em termos de valorização, os pontos internos à planície central formaram uma região com um potencial de acessibilidade privilegiado em relação aos pontos externos, que se situavam além das barreiras naturais a serem transpostas.

A primeira região nobre do núcleo urbano de São Carlos ocorreu em torno do marco inicial, como relata Neves (1983): "A zona residencial rica e elegante circunscrevia-se, em 1894, às proximidades do pátio da Matriz, estendendo-se pelas ruas margeantes, Visconde do Pinhal, 13 de Maio, Dona Alexandrina e do Carvalho. Ali se erguiam as melhores residências, fidalgas e com fumaças arquitetônicas." Devido à importância deste pólo inicial, instalaram-se em torno da região os prédios do governo, as principais escolas, os locais de trabalho das camadas mais ricas da época, os principais hotéis, o teatro, citando-se alguns exemplos. O fácil acesso a estes locais representa conveniência e favorece a valorização.

O valor da aglomeração urbana situou-se, a princípio, nas áreas mais acessíveis e convenientes em torno de um centro convergente, religioso, cívico e que incluía também espaços de consumo de luxo. As áreas mais distantes foram conseqüentemente menos valorizadas e inicialmente ocupadas pelas camadas sociais mais pobres, em um padrão de parcelamento do solo que tende a se beneficiar de vias de acesso pré-estabelecidas, em grande parte acessados pelas antigas estradas de chão.

Conforme Neves (1983), "a urbanização crescera mais em direção ao norte, para alcançar a esplanada mais promissora para edificações, onde teria nascido, se não o impedisse a teimosia do velho João Alves." Ao longo do tempo, as localizações que combinavam acessibilidade e um certo recolhimento, alcançando o topo da planície central a oeste da Rua São Carlos tenderam a ser mais valorizadas. Com a ocupação urbana ao norte, criou-se um eixo preferencial de expansão das moradias das camadas de alta renda, que segue rumos norte-oeste a partir do marco inicial.

A planície central é uma localização composta de determinada unidade envolvida pela barreira periférica formada pela hidrografia e reforçada pelo padrão de parcelamento, 
ocupação e uso do solo imediato. A exceção ocorre nas bordas da planície central que se localizam próximas à Avenida São Carlos, especialmente na seqüência de pontes que transpõem o Córrego Gregório. Nestes trechos, a barreira natural minimizou-se o bastante para que o uso, o padrão de parcelamento e de ocupação apresentem tal afinidade com a natureza comercial da Avenida.

\section{A IMPLANTAÇÃO DA FERROVIA}

A ferrovia e seus ramais não induziram a fundação do núcleo urbano em torno da estação, mas vieram interagir com um sistema de transporte pré-existente, composto pela malha urbana ortogonal que se instalava e as estradas de chão (Figuras 1 e 3).

O período ferroviário iniciou com a inauguração da ferrovia no ano de 1884 , prolongando-se até a construção da primeira rodovia, em 1955. Neste período de 71 anos cresceu consideravelmente a expressão de São Carlos no contexto regional. Simultaneamente à decadência da economia cafeeira, o final deste período ferroviário marca o estágio inicial da implantação de indústrias no município. A implantação da ferrovia marcou a ocupação da segunda planície, mais ampla e a sul da planície central. As linhas férreas implantaram-se nas regiões mais altas e nobres, atraindo os estabelecimentos produtivos e gerando o padrão arquitetônico industrial característico do município, quando visto a partir da planície central.

Os trilhos implantaram-se segundo o relevo. Inicialmente, o traçado procurou otimizar o desempenho da composição, combinando a capacidade do motor e a distância entre os trilhos (bitola). O estágio tecnológico inicial no qual se encontrava o transporte ferroviário no momento da sua implantação em São Carlos gerou traçados tortuosos. A maior parte destes trechos transformou-se em ruas urbanas e estradas municipais. Mais tarde houve substituições pela bitola larga na Estrada de Ferro Paulista, o que mitigou em parte a preponderância do relevo. 


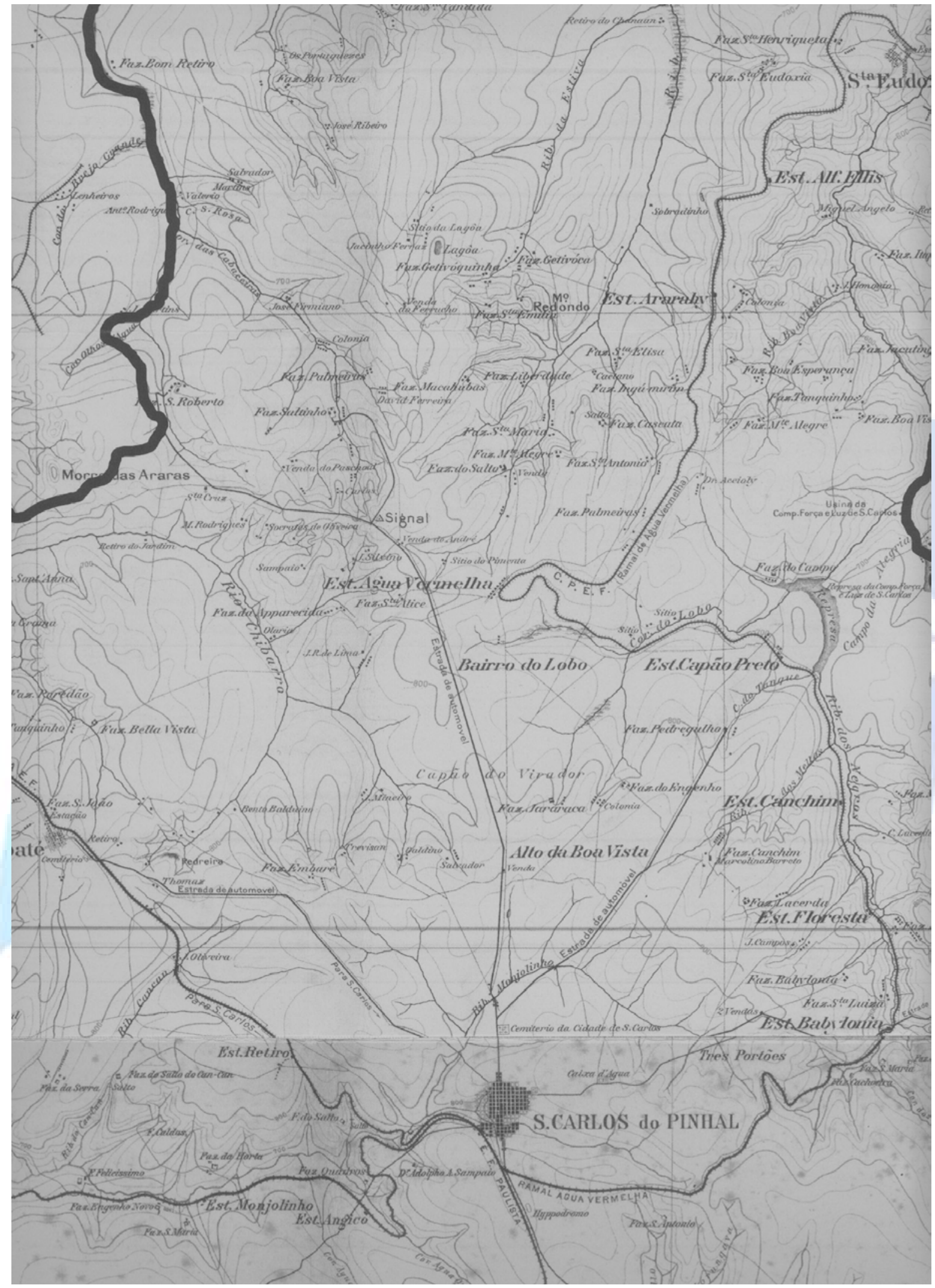

Fonte: TRUZZI (2004)

FIGURA 3. Implantação da área urbana ao sul do município ainda sem a Vila Prado. 
A ferrovia inaugurou um novo sistema de transporte cuja acessibilidade se concretiza pontualmente, em estações. Na sede do núcleo urbano, a única estação de passageiros comportava as estruturas para o controle do acesso público, embarque e desembarque de passageiros, polarizando a atração de fluxos intra-urbanos e induzindo a transposição da planície central a sul.

A ferrovia representou um potencial de acessibilidade de passageiros e mercadorias no ambiente regional, mas também incorporou um sério obstáculo para transposição intra-urbana. Esta barreira impõe-se no topo da planície, de forma contínua. As vias cortadas pela ferrovia e seus ramais perdem a disponibilidade para transposição em alguns horários do dia. Transpor a ferrovia representa inconvenientes que fizeram com que as regiões além das barreiras se tornassem desvalorizadas.

Ressalta-se que a ferrovia atrai padrões de uso e parcelamento do solo para fins produtivos, com os lotes maiores tendendo a localizarem-se mais próximos ao leito da ferrovia.

Cabe resumir que em nenhum lugar da planície ferroviária houve um bairro residencial de elites, face à prevalência da ocupação da ferrovia e das atividades fabris, formando uma barreira dupla em conjunto com o Córrego do Gregório. Quanto as externalidades de vizinhança, as elites desprezam o lado além da barreira, que será ocupada pela moradia das camadas populares, sendo a Vila Prado um exemplo expressivo da formação de um sub-centro. $\mathrm{O}$ valor de uso dos espaços produtivos neste período se manterá enquanto prevalecer o paradigma da ferrovia.

A partir de então, o automóvel substituirá gradativamente a estrada de ferro. As rodovias iniciaram um novo contexto com conseqüências para a ocupação do território e a formação do valor do solo urbano.

\section{A BARREIRA RODOVIÁRIA}

O período das rodovias iniciou em 1955 com a construção da antiga rodovia Anhangüera, posteriormente denominada Washington Luiz (SP-310), constituindo o principal paradigma rodoviário no município de São Carlos (Figuras 1 e 4). O traçado original da SP-310, de pista única, procurou distanciar-se da aglomeração urbana à época, enquanto reafirmava o eixo noroeste-sudoeste de comunicação regional. Atualmente, a pista dupla, separada por valas ou muros de concreto e a alta velocidade permitida caracterizam a barreira que oferece sérios riscos para transposição.

Os paralelos estabelecidos entre esta barreira e a ferroviária revelam semelhanças nos processos de desvalorização do solo urbano. A transposição da rodovia expõe a muitos inconvenientes ao tráfego intra-urbano, com risco de morte. Diretamente, a barreira se evidencia em si mesma, pela ruptura e descontinuidade espacial dos cortes e aterros, pela indisponibilidade de passarelas para pedestres e também pelas características dos viadutos, passagens subterrâneas, pontilhões e trincheiras. 
A rodovia atrai padrões de porte dos lotes e de uso do solo. Indiretamente, a barreira se acentua pela concentração de grandes terrenos privados que se valem do acesso à via regional. Os terrenos contíguos às rodovias têm sido valorizados à medida que potencializam os usos afins à esfera regional.

O traçado da SP-310 apresenta certa dependência com relação à capacidade dos motores. Esta, dentre uma série de variáveis a considerar, resultaram no traçado atual, que procurou minimizar declividades, ocupando em alguns trechos o topo da planície onde se implantou.

Desde o início da ocupação do território a planície onde se instalou o bairro do Tijuco Preto (Figura 4) tem todas suas localizações potencialmente menos valorizadas que a planície central, por demandar a transposição do Córrego do Tijuco Preto. A implantação da SP-310 próximo ao topo desta planície fez com que as regiões situadas além fossem, a princípio, ainda mais desvalorizadas.

A rodovia SP-310 interceptou todas as antigas estradas que seguiam rumo norte (Figuras 1 e 4). Destas seis transposições, quatro foram feitas sob o nível do seu pavimento, o que tem comprometido seriamente a valorização do solo.

Nota-se nas Figuras 1 e 4 que a rodovia Eng. Thalles de Lourena Peixoto (SP318) apresenta as melhores condições de transposição da rodovia Washington Luiz, sobre o nível. Adicionalmente, o acesso ao centro é potencializado pela continuidade do traçado da Avenida São Carlos. Assim, o constrangimento de transposição da SP-310 é praticamente nulo. Isto explica, em parte, a tendência representada pela valorização imobiliária das localizações contíguas a esta rodovia, tais como os condomínios residenciais Damha (Figura 4) bem como a exigência de espaço, que se torna cada vez mais escasso no interior da aglomeração. 


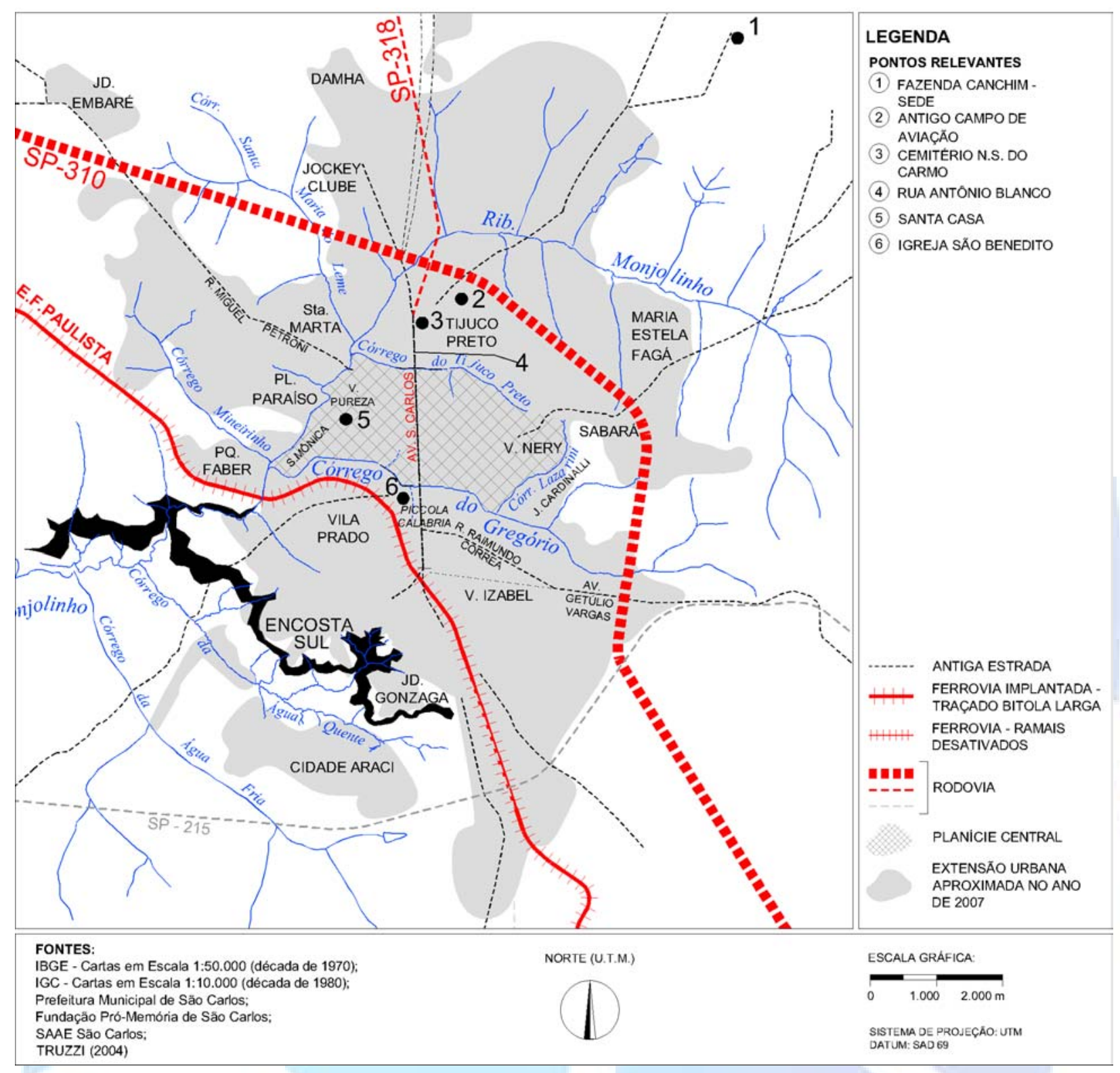

FIGURA 4. Localizações de bairros e pontos relevantes.

\section{A BARREIRA DUPLA}

Em menor escala, mas de forma análoga ao que foi observado por Villaça (2001), observa-se no núcleo urbano de São Carlos a formação de uma dupla barreira, composta por hidrografia e a ferrovia. Esta configuração faz com que a cidade seja dividida em dois lados: o "lado de lá" (além da ferrovia) e o "lado de cá", onde fica o centro tradicional. Forma-se um sub-centro popular imediatamente além da barreira, cujo principal exemplo é a Vila Prado. Nesta localidade relativamente "isolada" desenvolve-se uma aglomeração de comércio e serviços destinados a atender à demanda da vizinhança. É uma aglomeração bem menos diversificada que o centro principal. Pressupondo que a ferrovia e rodovia são análogas, os exemplos mais 
expressivos destes sub-centros são o grande Maria Estela Fagá e o Jardim Jockey Clube. O recém-criado Jardim Embaré (Figura 4) tem grandes possibilidades de formar futuramente um sub-centro .

\section{A BARREIRA DA ENCOSTA SUL}

Destaca-se que a proximidade da moradia às barreiras ferroviária ou rodoviária viabiliza ao menos a acessibilidade a possíveis locais de trabalho, uma vez que o acesso ao centro principal é relativamente remoto. Quando a barreira não é de natureza produtiva e encontra-se mais longe do centro, como é o caso da encosta sul (Figuras $1 \mathrm{e}$ 4), as conseqüências da exclusão são ainda mais sensíveis. Na aglomeração que se forma além predominam as sub-habitações. A diversificação de comércio e serviços é mínima e não chega a formar um sub-centro. Neste contexto instalam-se o Jardim Gonzaga no alto do despenhadeiro e o grande Cidade Araci, no pé da encosta (Figura 4).

\section{AS ANTIGAS ESTRADAS}

As condições naturais da bacia do Ribeirão Monjolinho, em especial as águas e o relevo, exerceram a dupla influência ao oferecer as potencialidades de ocupação e os obstáculos para a transposição dos cursos d'água.

A combinação da rede hidrográfica da bacia do Ribeirão Monjolinho e as antigas estradas podem ser observadas na Figura 1, juntamente com a disposição radial das antigas estradas, bem como certo equilíbrio na cobertura de $360^{\circ}$ em torno do marco inicial e da planície central.

Antes dos meios motorizados, o transporte foi feito quase exclusivamente pelas antigas estradas de chão, cujas datas de origem perdem-se no tempo. Contudo, o traçado destas estradas revela a lógica da sobrevivência e do menor esforço para locomoção. Em geral, as antigas estradas e caminhos buscam as menores declividades, sendo freqüente o traçado acompanhar os divisores de bacias, onde praticamente inexistem obstáculos.

As antigas estradas de chão tiveram grande influência na estruturação intraurbana. Em São Carlos, todas estas vias de longo alcance que ligavam o núcleo central transformaram-se em ruas urbanas, atraindo quase sem exceção os bairros e parcelamentos das camadas populares. Citam-se: Vila Nery, Vila Izabel, Vila Pureza, Tijuco Preto e Vila Prado (Figura 4). Para as elites, a proximidade às estradas parece não ser desejável, na medida em que expõe a moradia ao grande fluxo de viajantes anônimos.

Em termos morfológicos, os vestígios da ocupação não planejada e popular ao longo destas estradas expressam-se através do desalinhamento e desnivelamento entre o pavimento da via e o acesso às edificações. 


\section{DIFERENCIAIS DE EXPANSÃO URBANA}

No período pré-ferroviário o primeiro movimento de expansão do núcleo urbano de São Carlos do Pinhal ocorreu ao sul do marco inicial, no vale do Córrego do Gregório, representando a primeira transposição da planície central. É desta época a localização do primitivo cemitério, onde atualmente encontra-se a igreja de São Benedito (Figura 4).

Em 1867, Dona Alexandrina viabilizou o crescimento da cidade rumo norte, mantendo-se a continuidade da malha ortogonal.

Em 1884, a ferrovia induziu a expansão novamente a sul. A Estação ferroviária de passageiros passou a polarizar fluxos intra-urbanos. Inicialmente, a ocupação produtiva, de características fabris ou incipientemente industriais, voltadas à ferrovia concentrou-se nas imediações da estação e principalmente em torno da Piccola Calabria (Figura 4), na baixada do Gregório. As moradias populares tenderam a se concentrar próximas às unidades produtivas.

Segundo Braga (1894), no ano de 1889 Joaquim Alves de Souza Nery e sua esposa fizeram a doação da gleba onde encontra-se a Vila Nery (Figura 4). Neste mesmo ano "estabeleceu-se na cidade e município rêde de linhas telephonicas" ... "com que a Camara contractou a canalisação da agua da Biquinha" ... "melhoramento este inaugurado um anno depois" e doam-se outras terras à Câmara Municipal, na sesmaria do Monjolinho.

Conectada diretamente à malha ortogonal, a leste da planície central, a estrada da Babilônia estruturou o crescimento urbano ao longo da Vila Nery, atraindo uma série de pequenos loteamentos e parcelamentos que se utilizavam do acesso (Figuras 1 e 4). A Vila Nery foi marcada pela ocupação popular, formando um sub-centro de comércio e serviços, próximo ao antigo Balão do Bonde (hoje Praça ARCESP). Este sub-centro popular, próximo à estrada e relativamente longe do centro, encontra-se no limite da planície central, em seu extremo leste.

Com o objetivo de descrever resumidamente o crescimento urbano nas regiões contidas além da planície central e aquém da ferrovia e da rodovia SP-310, a seqüência priorizará uma ordem radial, em sentido horário, partindo-se do rumo norte. Assinalada a questão da barreira dupla formada pelo rio e a ferrovia, cabem algumas observações sobre a evolução do centro principal de São Carlos.

Partindo-se do marco inicial (Figura 1), houve um vetor preferencial norte-oeste de ocupação das moradias das camadas de alta renda. Nesta pequena fração angular dentro da cobertura de $360^{\circ}$ em torno do marco inicial o centro permanece com renovação arquitetônica geral e forte tendência à verticalização. Na fração angular complementar, o centro é ocupado predominantemente pelo comércio popular e pelas camadas médias e pobres da população. Observa-se a tendência do esvaziamento e subutilização de edificações, desinteresse na sua renovação e conservação, com um conseqüente aprisionamento do valor de uso dos imóveis. Desertificação noturna e prostituição são espécies de sintomas de "desvitalização". O consumo de luxo tende a 
não se instalar nestas áreas, concentrando-se nas regiões mais nobres e no shopping center, indo ao encontro do vetor preferencial de expansão dos bairros das camadas mais ricas. A instalação dos campi da USP a noroeste e da UFSCar a norte vieram reafirmar este eixo. Desde o início, e não por acaso, a localização da Santa Casa, na Vila Pureza, (Figura 4) e a alta concentração circundante de consultórios médicos são exemplos da localização dos locais de trabalho de boa parte das elites neste vetor preferencial, assim como suas moradias, os principais prédios do governo, as escolas, o consumo diferenciado. O campus 2 da USP instala-se também neste vetor. Grosso modo, as direções norte e noroeste apontam para processos de "conurbação" com Ibaté e Água Vermelha.

De volta à expansão popular, em sentido norte, a transposição da planície central se deu por meio da continuação da Avenida São Carlos, rumo ao cemitério Nossa Senhora do Carmo (Figura 4). No ano de 1890, a primeira intendência nomeada pelo governo provisório do recém-proclamada República compra uma área de 4 alqueires de campos para transferir o cemitério que nesta época encontrava-se na Vila Nery. Conforme relata Braga (1894): "foi retirado de junto da cidade o serviço de enterramentos, colocando-se o cemitério a distancia respeitável, ao norte, entre o riacho Tijuco Preto e o ribeirão Monjollinho" (Figura 4). Nas proximidades do Cemitério Nossa Senhora do Carmo, a parte mais alta da planície abrigou por muitas décadas a pista do Clube de Aviação Salgado Filho (Figura 4). A formação do bairro do Tijuco Preto, ocupado por camadas mais pobres e de traçado bastante espontâneo, ocorreu contiguamente a estes equipamentos, diferindo radicalmente do padrão da malha ortogonal da planície central. Observa-se um conjunto de bairros populares, articulados pela Rua Antônio Blanco (Figura 4). Nesta rua, a morfologia característica do desnível e desalinhamento das construções e irregularidades da calçada denotam a ocupação não planejada além da planície central e a antiguidade da via. Nesta região, o traçado urbano apresenta uma série de desconexões, que em conjunto com a barreira representada pelo Córrego Tijuco Preto e o padrão atraído (indústrias, glebas), agravam a acessibilidade e comprometem a valorização do solo urbano.

Além do cemitério, a norte, acessavam-se os distritos de Santa Eudóxia e Água Vermelha e as diversas fazendas por meio de antigas estradas de chão e trilhas concorrentes. As duas estradas antigas rumo norte deram lugar a uma via contemporânea com melhores condições de tráfego, a SP-318, que dá acesso a Ribeirão Preto.

A estrada da Fazenda Canchim (Figuras 1 e 4) partia das proximidades do Cemitério Nossa Senhora do Carmo e contornava a planície, deixando livre o topo para outras atividades. Esta estrada atualmente dá acesso à entrada sul da Universidade Federal de São Carlos (Figura 1), e mais adiante à própria Fazenda Canchim. Assim como os demais campi são pólos de expressão mundial com reflexos nos espaços extra $\mathrm{e}$ intra-urbanos. Na escala intra-urbana de São Carlos tendem a valorizar o solo urbano próximo para as moradias dos diversos segmentos envolvidos. A Estrada da Fazenda Canchim tem a peculiaridade de não induzir ocupação residencial além da Rodovia SP310 . 
A rodovia SP-318 passa a ser um vetor importante da tendência de ocupação de bairros residenciais para camadas com maior poder aquisitivo. Destacam-se os condomínios residenciais que combinam a facilidade de acesso ao centro e à Universidade Federal de São Carlos (Figura 1), transpondo a rodovia SP-310 acima do pavimento.

Continuando o sentido radial horário, a leste, pela estrada da Babilônia além do ponto onde deixa a planície central, destaca-se o Parque Sabará (Figura 4), loteamento fechado de alto padrão, o primeiro a ser construído na área urbana e uma exceção aos vetores predominantes norte e oeste. Talvez a principal causa deste fechamento seja por estar localizado em uma periferia. Após a transposição sob o pavimento da Rodovia Washington Luiz, acessa-se o conjunto de bairros populares em torno do Conjunto Habitacional Maria Estela Fagá (Figura 4).

Continuando o sentido horário, entre a Estrada da Babilônia e o Córrego Gregório destacam-se uma grande gleba verde e o Jardim Cardinalli (Figura 4), loteamento residencial aberto voltado a camadas de padrão mais elevado, também uma exceção ao vetor preferencial. Por isto, pode não resistir a processos de desvalorização e igualar-se ao entorno predominante.

Rumo sudeste, o trecho inicial da antiga estrada de Descalvado corresponde atualmente à Rua Raimundo Correa e a aproximadamente o terço final da Avenida Getúlio Vargas (Figuras 1 e 4). Esta estrada possuía certas desvantagens originais, por localizar-se além da baixada do Gregório, localização já naturalmente desprivilegiada por ser menos acessível. Constata-se a morfologia do desnivelamento e desalinhamento e irregularidade das calçadas na Rua Raimundo Correa, bem como o adensamento de usos comerciais e de serviços. Por muitos anos o ramal de Água Vermelha (Figura 1) limitou esta via. Com a retirada do ramal, não houve prolongamento desta rua, que passou a ser limitada pela Avenida Getúlio Vargas.

Se uma ferrovia representa sérios obstáculos de transposição, a região que é delimitada por duas ferrovias sofre o duplo prejuízo de perda de acessibilidade e conseqüente desvalorização do solo. Isto pode se verificar na região além da Vila Izabel, contida entre a Estrada de Ferro Paulista e o Ramal de Água Vermelha (e em menor grau entre a Estrada de Ferro Paulista e o ramal de Ribeirão Bonito). Mesmo após a retirada do ramal da Água Vermelha, a ocupação fabril e industrial nesta região entre trilhos já estava consolidada. Menciona-se os pontos de tráfico e prostituição ao longo da Avenida Getúlio Vargas, fortes indicadores de desvalorização.

A sul e sudoeste, as antigas estradas de Brotas, do Arruda e a que conduzia a importantes fazendas antigas a sudoeste acessam o sub-centro da Vila Prado e os demais loteamentos contíguos a sudoeste. De todas, esta antiga estrada é a mais acidentada. Isto se deve à transposição do mais notável e antigo obstáculo natural, a imponente encosta sul.

Finalmente, rumo noroeste, a estrada de Araraquara (hoje Rua Miguel Petroni) fazia a ligação essencial com a primitiva sede e ao antigo Distrito de Ibaté (Figura 2). Observa-se a tendência de conurbação com o antigo distrito. De forma geral, a planície 
formada pelo Córrego Mineirinho e o Córrego Santa Maria do Leme abriga uma parte considerável de loteamentos destinados a camadas sociais de maior renda, tais como o Parque Faber, o Planalto Paraíso e Parque Santa Marta (Figura 4). Observa-se a leve tendência da verticalização das construções. Estes parcelamentos apresentam morfologias peculiares, não se ligando diretamente à Rua Miguel Petroni (Figura 4).

\section{CONCLUSÕES}

O presente artigo procurou reunir elementos espaciais para demonstrar por que São Carlos encontra-se no local onde está e como o valor esteve desde o início associado à acessibilidade ao centro convergente.

O transcorrer do crescimento da aglomeração é marcado por diversas tendências. No entanto, os movimentos não ocorrem por acaso. Não basta interpretar as estatísticas censitárias, mas compreender como e por que se dão os padrões espaciais de distribuição de riqueza e pobreza pelo solo urbano. É preciso, nas palavras de Villaça (2001), "explicar as localizações intra-urbanas", freqüentemente recorrendo-se à História e Geografia locais.

A geografia local influi diretamente sobre os processos de estruturação intraurbana, a começar pelos obstáculos ou os atrativos naturais do território. As feições naturais são importantes, porém não são decisivas para o valor do lote urbano. A cidade, como produto humano, tem sua própria lógica de valorização. São Carlos do Pinhal é fundada sobre campo e mata e a daí em diante instaurou-se o valor da localização pura.

Neste artigo, o topo das planícies foi destacado, demonstrando como tem sido ampla a liberdade de escolha e ocupação das localizações das estruturas produtivas e dos bairros residenciais de alto padrão.

Discorreu-se sobre o impacto que as infra-estruturas de transporte regional têm exercido sobre o transporte intra-urbano de pessoas e na conseqüente desvalorização dos imóveis afetados por estas barreiras. As motivações são regionais, mas as externalidades negativas destas estruturas são de fato um problema intra-urbano e dos governos locais. Mensurar as médias da desvalorização que estas estruturas acarretam pode trazer luz sobre diversos problemas a serem enfrentados pelas políticas tributárias e urbanísticas, tais como a gestão do valor do solo urbano, a avaliação contextualizada dos vazios e os processos de "desvitalização" dos centros principais.

\section{REFERÊNCIAS}

BRAGA, C. C. S. Contribuição ao estudo da história e geografia da cidade e município de São Carlos do Pinhal. In: Almanach de São Carlos, de 1894. Joaquim 
Augusto (Org). São Carlos, Typographia Aldina, 1984, p XII. São Carlos: Associação de Escolas Reunidas - ASSER, 1994. (Série Documentos).

NEVES, A. P. das. O Jardim Público de São Carlos do Pinhal. São Carlos, Fundação Theodoreto Souto, 1983.133p.

SANTOS, M. Economia Espacial: Críticas e Alternativas. Tradução. M. I. Q. F. Szmrecsányi. ${ }^{\text {a }}$. Ed. São Paulo: Editora da Universidade de São Paulo, 2003. 204p. (Coleção Milton Santos).

TRUZZI, O. M. S. (Org). Fontes estatístico-nominativas da propriedade rural em São Carlos 1873-1940. São Carlos: EdUFSCar, 2004. 212p. (Coleção Nossa História).

VILLAÇA, F. Espaço Intra-Urbano no Brasil. São Paulo: Studio Nobel, 2001. 376p. 